\title{
High Temperature Degradation in Power Plants and Refineries
}

\author{
Heloisa Cunha Furtado ${ }^{\mathrm{a}} *$, Iain Le May ${ }^{\mathrm{b}} *$ \\ ${ }^{\mathrm{a}}$ CEPEL, Centro de Pesquisas de Energia Elétrica \\ C.P. 2754, Cidade Universitaria, 20001-970 Rio de Janeiro - RJ, Brazil \\ ${ }^{\mathrm{b}}$ Metallurgical Consulting Services Ltd. \\ P.O. Box 5006, Saskatoon, SK S7K 4E3, Canada
}

Received: September 2, 2002; Revised: September 4, 2002

\begin{abstract}
Thermal power plants and refineries around the world share many of the same problems, namely aging equipment, high costs of replacement, and the need to produce more efficiently while being increasingly concerned with issues of safety and reliability. For equipment operating at high temperature, there are many different mechanisms of degradation, some of which interact, and the rate of accumulation of damage is not simple to predict. The paper discusses the mechanisms of degradation at high temperature and methods of assessment of such damage and of the remaining safe life for operation.
\end{abstract}

Keywords: degradation mechanisms, high temperature, life assessment, power plants, refineries

\section{Introduction}

Thermal power plants and refineries around the world are aging and need to be assessed to ensure continued safe operation. Replacement is frequently not an option because of high capital costs, and the much lower cost of continuing the operation of the older plant. However, reliability and safety are issues that have become much more important in recent years, so the assessment of damage and of the risk associated with failure have become increasingly important. In order to make such assessments on a sound basis, it is necessary to know the potential mechanisms of degradation and the rate of accumulation of damage that may be expected with each.

\section{Deterioration mechanisms}

The principal deterioration mechanisms in high temperature plant are creep damage, microstructural degradation, high temperature fatigue, creep-fatigue, embrittlement, carburization, hydrogen damage, graphitization, thermal shock, erosion, liquid metal embrittlement, and high temperature corrosion of various types. Additionally, stress corrosion cracking and aqueous corrosion may be problems although these damage mechanisms are not generally expected in high temperature components: however they may occur when

*e-mail: heloisa@cepel.br, lemayi@metallurgicalconsulting.net Presented at the International Symposium on High Temperature Corrosion in Energy Related Systems, Angra dos Reis - RJ, September 2002. components are cooled down and liquid is still present within or in contact with them. Aspects of each will be considered in turn.

\subsection{Creep}

Creep is one of the most serious high temperature damage mechanisms. It involves time-dependent deformation and high temperature creep cracking generally develops in an intercrystalline manner in components of engineering importance that fail over an extended time. These include boiler superheater and other components operating at high temperature, petrochemical furnace and reactor vessel components and gas turbine blades. At higher temperatures, as can occur with local overheating, deformation may be localized, with large plastic strains and local wall thinning. At somewhat lower temperatures and under correspondingly higher stress levels, fracture can be transgranular in nature. To characterize the type of deformation and the relevant fracture mechanisms to be expected or to correlate observed deformation and fracture characteristics with probable operating conditions, deformation and fracture mechanism maps as developed by Ashby ${ }^{1}$ and Mohamed and Langdon ${ }^{2}$ can be useful in this regard. 
Classification of creep damage in steam generators has been made using the largely qualitative approach of Neubauer and Wedel ${ }^{3}$ based on the distribution of creep voids and microcracks observed by in situ metallography, and illustrated schematically in Fig. 1. However, as has been shown subsequently, the method is unreliable for CrMo steels, at least, as apparent voids may be developed during the polishing and etching sequence ${ }^{4-5}$. Replica metallography is useful, however, and the degree of spheroidization of carbides in bainitic and pearlitic structures can provide a good indication of the degree of thermal exposure and can be correlated with the extent of creep damage ${ }^{6}$. Used in conjunction with hardness measurements, indicating loss of tensile strength, these semi-quantitative tools have served to allow estimates of remaining safe life to be made of components undergoing damage by creep.

\subsection{Microstructural degradation}

Microstructural degradation is a damage mechanism that can lead to failure by some other process such as creep, fatigue or more rapid fracture. It is important that it is recognized as a mechanism of damage as it can result in a significant loss in strength in a material. It is appropriate to discuss this following directly upon the discussion of creep damage, because the two mechanisms are closely bound together and, indeed, are difficult to separate. It has already been noted that $\mathrm{Cr}$-Mo steels that are liable to fail by creep in a short time may display spheroidization of the carbides but little, if any, void formation. The formation of voids appears, in many cases, to be a very local phenomenon occurring very close to the time of fracture. It is worth commenting that the approach of Kachanov ${ }^{7}$ to the accumulation of damage (the continuum damage approach), postulating a loss of effective area or a loss in resistance to deformation, does not require any actual voids or loss of crosssection, and microstructural damage may be the dominant aspect of reduction in creep strength. Thus, evaluation of the potential for creep failure and the extent of creep damage needs to take account of microstructural changes. This may be done directly or through a measurement of the change in hardness, as this quantity provides an indication of the resistance of a material to deformation. Recently, Dyson $^{8}$ has discussed continuum damage mechanics modelling of creep in terms of several damage mechanisms, including microstructural degradation.

Another example of microstructural degradation is decarburization of carbon or alloy steel when exposed to an oxidizing atmosphere at high temperature. There is a loss of strength in the surface layer of the steel.

\subsection{High temperature fatigue and thermal fatigue}

Fatigue, involving repeated stressing, can lead to failure at high temperature as it does at low temperature. In com- ponents operating at high temperature it often arises through temperature changes that can lead to cyclic thermal stresses. This can lead to thermal fatigue cracking. The cracking tends to develop in areas of high constraint, and the detailed mechanism may be one of local creep deformation.

Figure 2 shows the initiation of cracks at the interface between CrMo ferritic steel and austenitic stainless steel tubes at the entrance to the outlet header of the secondary superheater of a boiler operating at $540{ }^{\circ} \mathrm{C}$ and which had been subjected to frequent shut-downs and start-ups ${ }^{9}$. The unit was designed for continuous operation as are most steam generators, and the difference in the coefficients of thermal expansion between the ferritic and austenitic tubes has led to the cracking. Figure 3 shows cracking along the fusion line at a stub attached to the header.

\subsection{Creep-fatigue}

Creep-fatigue interaction is a complex process of damage involving creep deformation and cyclic stress and the predominant damage mode can range from primarily fa-

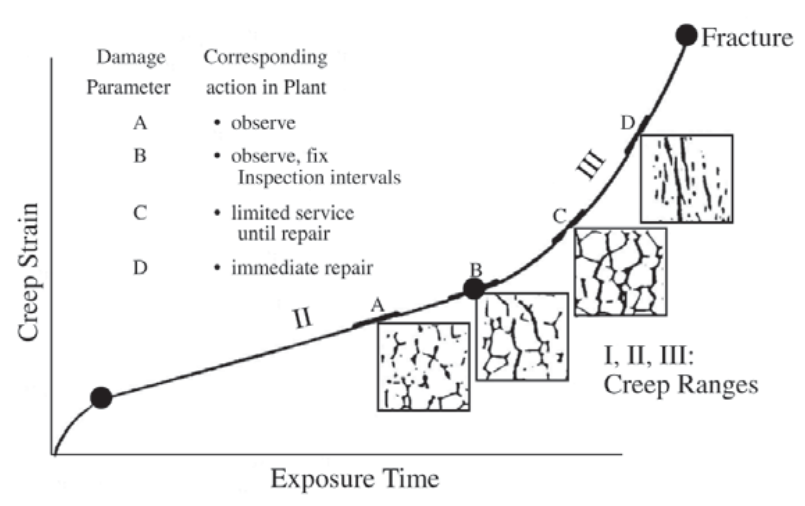

Figure 1. Neubauer's classification of creep damage from observation of replicas and consequent action to be taken.

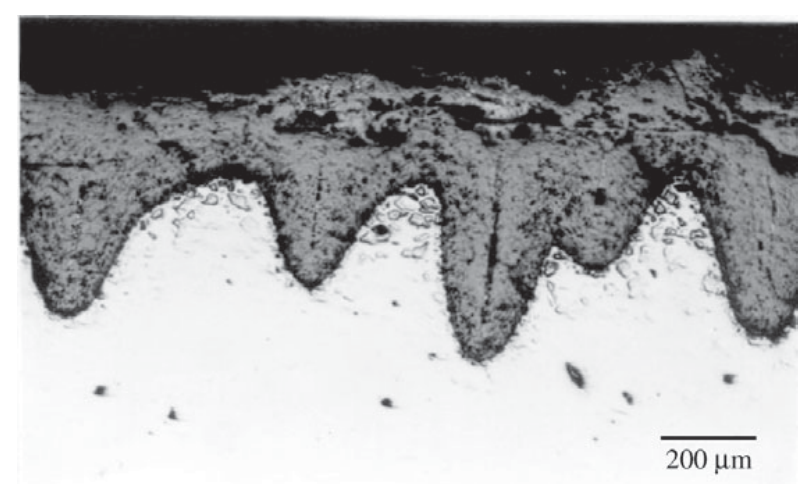

Figure 2. Thermal fatigue cracking at a ferrite-austenite junction. 
tigue crack growth at higher frequencies and lower temperatures to primarily creep damage where hold times are long and temperature is at the high end of the scale.

\subsection{Embrittlement and carburization}

Embrittlement from precipitation can arise in a number of different ways. For example, sigma phase formation in austenitic stainless steels maintained at high temperature or cycled through the critical temperature range (approximately 565 to $980{ }^{\circ} \mathrm{C}$ ) causes loss of ductility and embrittlement. Ferritic stainless steels may be subject to an embrittlement phenomenon when held at or cooled over the temperature range 550 to $400{ }^{\circ} \mathrm{C}^{10}$. If the temperature conditions are considered likely to lead to such effects, metallographic checks are advisable after extended exposure prior to an unexpected rupture developing. In addition to the embrittlement of ferritic steels exposed to high temperature during service, and of austenitic stainless steels through the formation of sigma phase, carburization can produce brittle material when a component is exposed to a carburizing atmosphere for extended time at high temperature. Figure 4 shows extensive carbide formation in the hot gas casing of a gas turbine used for peak load power generation after $18,000 \mathrm{~h}$ of operation, involving 1,600 operating cycles. With a gas-side temperature of $985^{\circ} \mathrm{C}$ and an air side temperature of $204{ }^{\circ} \mathrm{C}$, the 321 stainless steel had developed severe thermal (fatigue) cracking. The cracks had initiated at the brittle, carburized gas side surface, the material having little resistance to bending without cracks occurring.

\subsection{Hydrogen damage}

Hydrogen damage, arising particularly in petrochemical plant, can occur in carbon steels through diffusion of atomic hydrogen into the metal, where it combines with the carbon in the $\mathrm{Fe}_{3} \mathrm{C}$ to form methane and to eliminate the

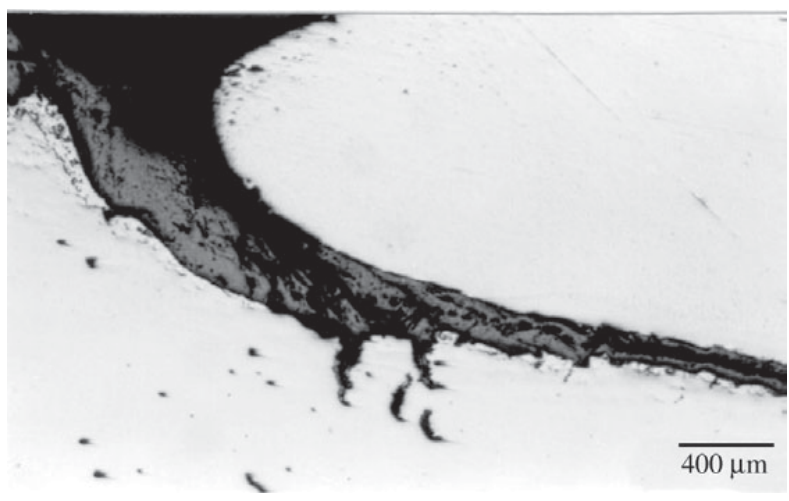

Figure 3. Cracking on the fusion line on the stub side (left). pearlite constituent. This is a special case of microstructural degradation, and is much less common today than in the past because of the use of low-alloy steels containing elements that stabilize carbides. Figure 5 shows carbon steel from a catalytic cracking unit. Carbide from the original pearlite has been converted to methane, producing voids. In fact, recrystallization of the ferrite was observed around some of the voids, produced by the combination of deformation under pressure of the methane and the elevated temperature. The steel had been subjected to a temperature during service that was higher than appropriate for the grade of steel employed.

Hydrogen-assisted cracking is a potential problem in petroleum reactor pressure vessels in hydrogen service, and the concern is that such sub-critical cracks do not reach a critical size for failure. Relations are available to estimate crack growth rates, and the important matter is the ability to detect and measure accurately the depth of such cracks lying beneath stainless steel cladding so that accurate predictions can be made.

\subsection{Graphitization}

Graphitization can take place in ferritic steels after exposure to high temperature for extended time, owing to reversion of the cementite in the pearlite to the more stable graphite phase. It is a particular form of microstructural degradation that was formerly observed relatively frequently in petrochemical components. With the development of more stable CrMo steels, it is not often seen today, but occurs from time to time both in petrochemical plant and in

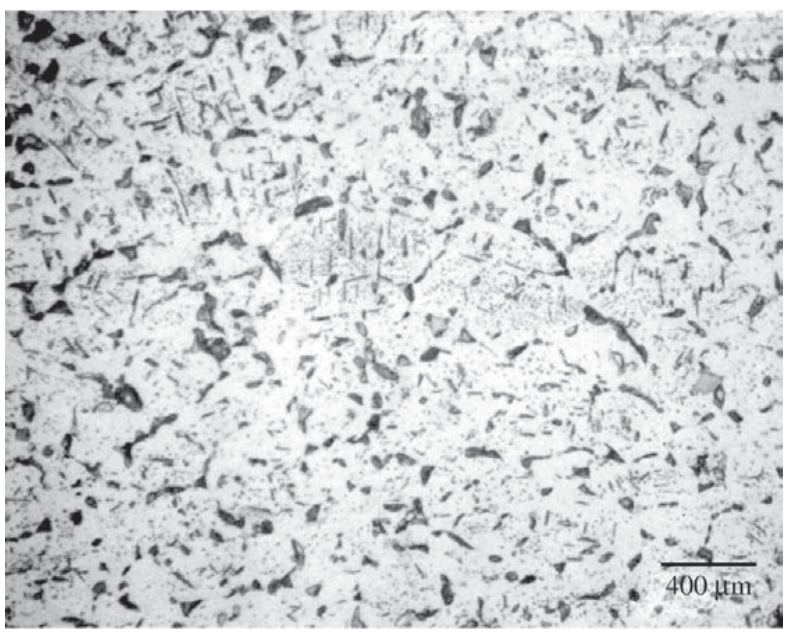

Figure 4. Grain boundary and intragranular precipitation at the hot side of the hot gas casing of a gas turbine. Material: 321 stainless steel. Etched successively in Vilella's reagent, methanolic aqua regia, and Groesbeck's reagent to darken carbides. 


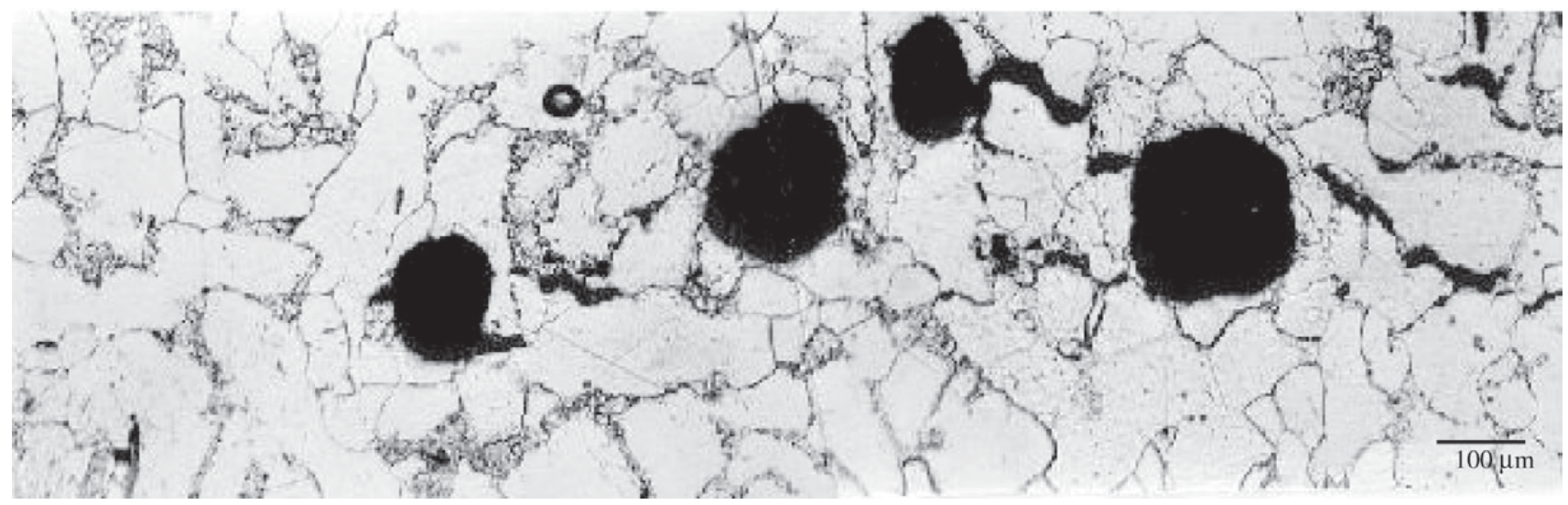

Figure 5. Voids formed by methane in a carbon steel exposed to a hydrogen atmosphere at high temperature. The carbides in the pearlite have been eliminated by reaction with the hydrogen. Photograph courtesy of T.L. da Silveira.

steam generators in which the temperature is high and the material is not entirely stable.

Figure 6 shows graphitization in a steam pipe of DIN $15 \mathrm{Mo} 3$ alloy steel at the exit of a superheater at a nominal operating temperature of $480{ }^{\circ} \mathrm{C}$. The tube suffered a local failure in the form of a "window" after some 100,000 h of service. Clearly the temperature was in excess of that which the material could withstand without serious deterioration.

Fracture occurred along planes of graphite nodules, with decohesion between the graphite and the ferrite matrix, these regions linking together from the growth of creep cracks as shown in Fig. 7. The formation of graphite in local planes or lines is believed to be due either to banding in the original structure or to local cold working during tube straightening, as can occur when Lüder's bands are produced.

\subsection{Thermal shock}

Thermal shock involves rapid temperature change producing a steep temperature gradient and consequent high stresses. Such loading can produce cracking, particularly if the shock loading is repetitive. Cracks generated in this manner progress by a process of thermal fatigue. Such conditions are not encountered in thermal generating plants and refineries under normal operating conditions, but may arise during emergencies or with an excursion in the operating conditions. Brittle materials are much more susceptible to thermal shock and ceramic components, as are becoming more common in advanced gas turbines for example, are susceptible to such damage.

\subsection{Erosion}

Erosion can occur in high temperature components when there are particles present in flowing gases. This is a not uncommon situation in coal-fired power plants in which erosion by fly-ash can lead to tube thinning and failure in

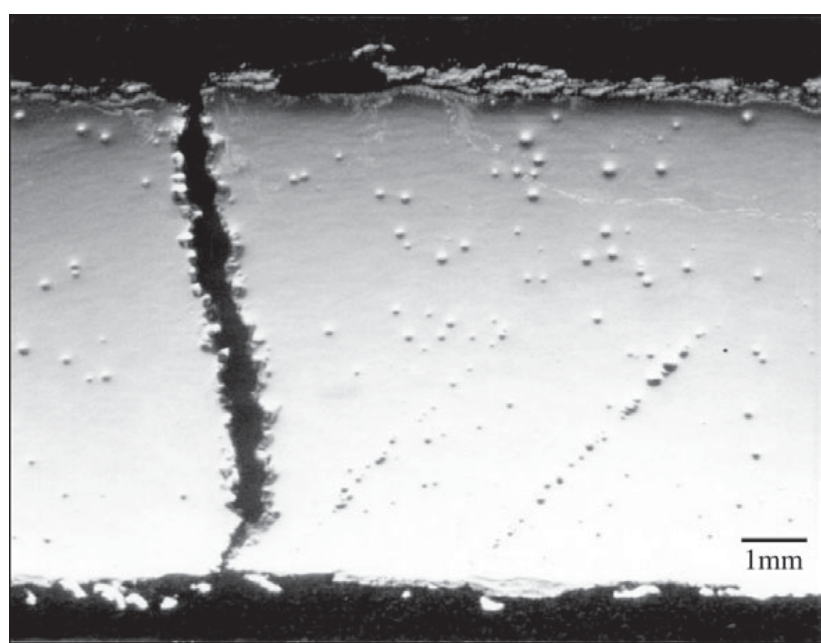

Figure 6. Aligned graphite nodules that led to cracking in a superheater outlet pipe.

economizers and reheaters, and sootblower erosion can produce thinning in superheaters and reheaters in those tubes that are in the paths of the blowers. The solution to fly ash erosion depends in part on improving boiler flue gas distribution, and cutting down on local excessively high gas velocities. The control of soot blower erosion depends on many factors including excessive blowing pressure, poor maintenance and the provision of effective tube protection where required.

\subsection{Liquid metal embrittlement (LME)}

The classic example of liquid copper metal embrittlement of steel is shown in Fig. 8, where the $\mathrm{Cu}$ has penetrated along the austenite grain boundaries when the carbon steel was at a temperature of $1100^{\circ} \mathrm{C}$. 
Liquid metal embrittlement can occur with a number of liquid-solid metal combinations, and one that can have serious consequences for the refining industry is LME of austenitic stainless steel by zinc. Rapid embrittlement can occur at temperatures above $750{ }^{\circ} \mathrm{C}$, and has been observed to produce widespread cracking in stainless steel components after a fire when there is a source of $\mathrm{Zn}$ present such as galvanized steel structural parts, or when there is contamination from Zn-based paints ${ }^{11}$. This latter source led to considerable cracking at the time of the Flixborough disaster ${ }^{12}$. Cracking can be extremely rapid $(\mathrm{m} / \mathrm{s})$ and stress levels can be as low as $20 \mathrm{MPa}$ for such cracking to take place ${ }^{13}$.

Two types of attack are believed to occur in the process of Zn-embrittlement of austenitic stainless steel ${ }^{14}$, as illustrated in Fig. 9. Type 1 embrittlement is a relatively slow process, controlled by the rate of diffusion along austenite grain boundaries, and involves the combination of $\mathrm{Zn}$ with $\mathrm{Ni}$, this producing $\mathrm{Ni}$-depleted zones along the boundaries. As a consequence, the FCC austenite structure transforms to BCC ferrite, producing expansion and a stress that initiates cracking. Type 2 embrittlement occurs at a much faster rate, requiring an external stress to facilitate crack initiation. Cracking will not occur in the presence of a substantial oxide film unless this is ruptured locally.

Figure 10 shows an example of LME cracking by $\mathrm{Zn}$ in an austenitic steel as a result of a fire in a refinery and the

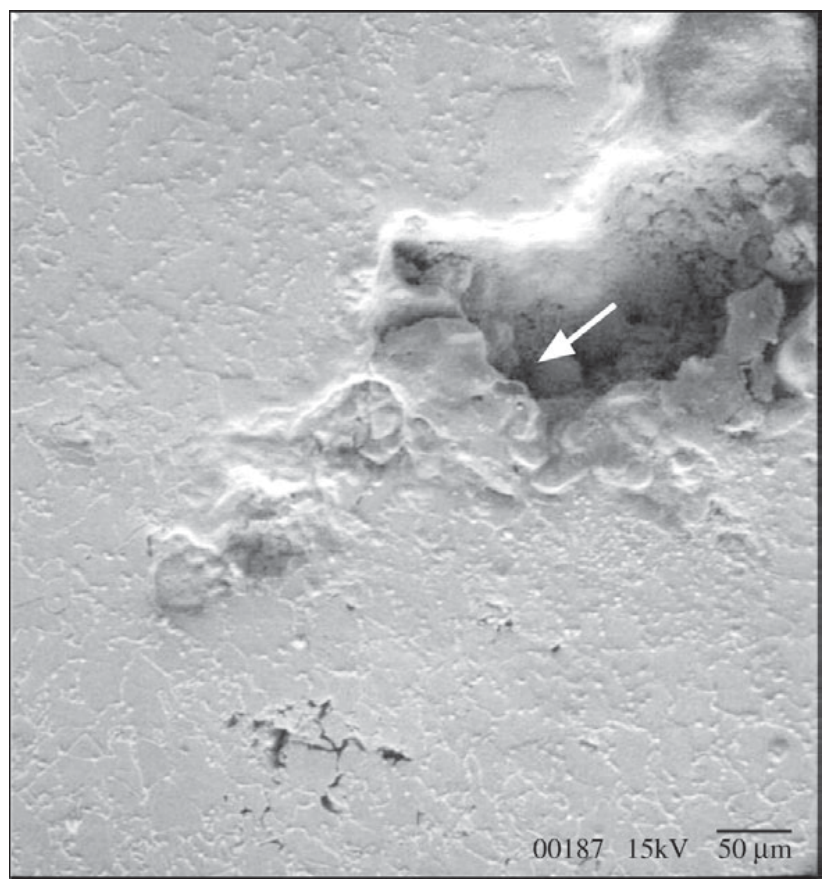

Figure 7. Local voids near the crack tip (shown by the arrow) in graphitized steel. formation of molten $\mathrm{Zn}$ from a galvanized component on the stainless steel tubing. The resemblance to the crack morphology of stress corrosion cracking is obvious.

\subsection{High temperature corrosion}

Minimization of corrosion in alloys for high temperature applications depends on the formation of a protective oxide scale. Alternatively, for alloys with very high strength properties at high temperature, a protective coating may need to be applied. The oxides that are generally used to provide

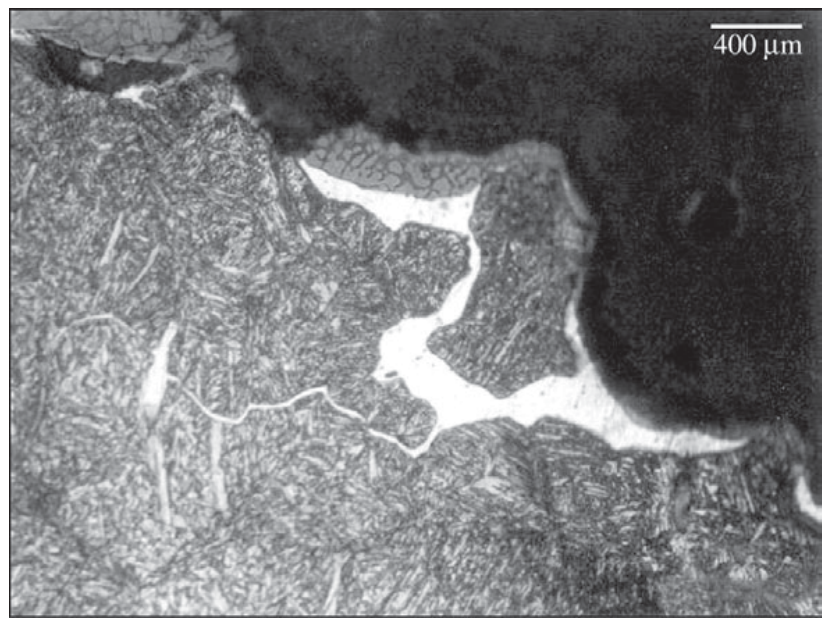

Figure 8. $\mathrm{Cu}$ embrittlement of carbon steel at $1100{ }^{\circ} \mathrm{C}$.

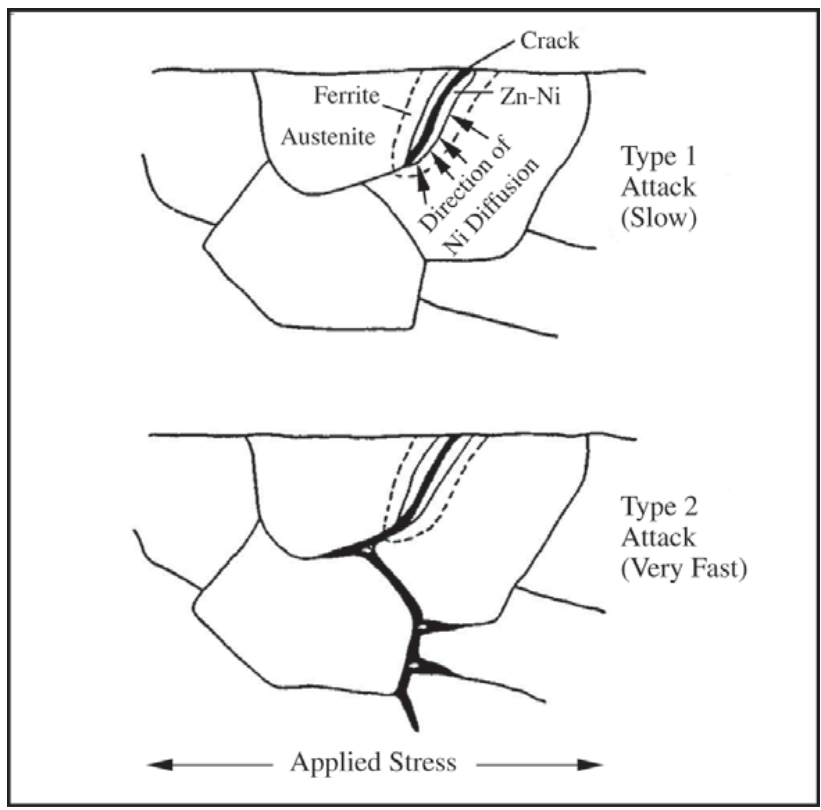

Figure 9. Schematic drawings of the two types of LME by $\mathrm{Zn}$ in austenitic stainless steel. 
protective layers are $\mathrm{Cr}_{2} \mathrm{O}_{3}$ and $\mathrm{Al}_{2} \mathrm{O}_{3}$. Corrosion protection usually breaks down through mechanical failure of the protective layer involving spalling of the oxide as a result of thermal cycling or from erosion or impact.

High temperature corrosion can also occur by carburization or sulphidation. As has already been discussed, carburization takes place in carbon-rich atmospheres such as in reformer or other furnaces and the surface layer of the alloy can become brittle, leading to the formation of cracks, particularly when there are severe or cyclic temperature changes and this can greatly reduce the strength of the component. Sulphidation can be a serious problem in nickel-

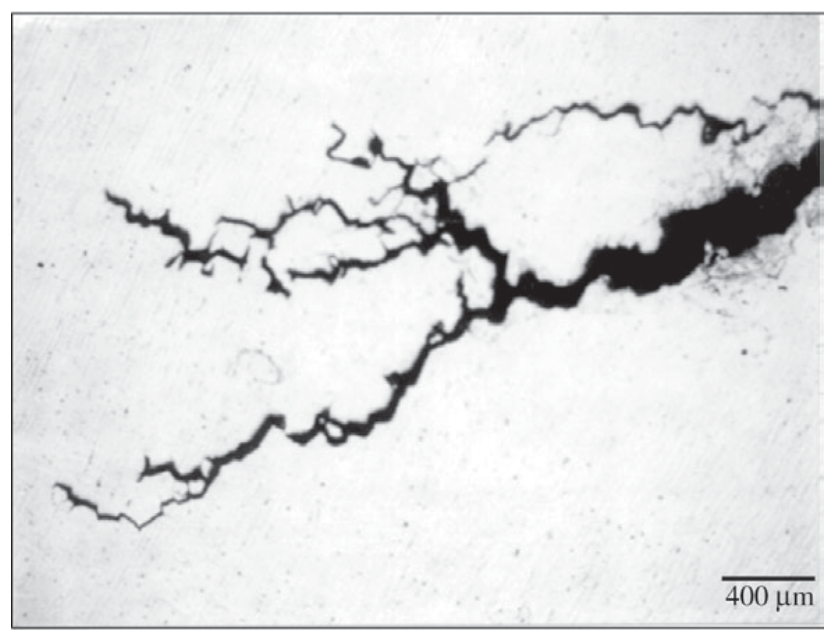

Figure 10. LME cracking of austenitic stainless steel by molten Zn. based superalloys and austenitic stainless steels, with sulphides forming on grain boundaries and then being progressively oxidized, with the sulphides moving ahead along the grain boundaries, so causing embrittlement in the alloy.

\subsection{Stress corrosion cracking and aqueous corrosion}

As indicated earlier, these are not damage mechanisms that are normally associated with components operating at high temperature. However, when shutdown of a plant occurs, fluid may condense and there may be water containing contaminants within pipes or vessels in the plant. The corrosion or stress corrosion cracking that occurs at low temperature may lead to preferential damage at high temperature during later operation of the plant.

Cracking that initiated in the inlet header of a primary superheater at the stub attachments is shown in Fig. 11. The cracks are thought to have grown by a combination of stress corrosion cracking during shutdown periods as well as by thermal cycling of the boiler, although the initiation in this case is believed to have been caused by thermal fatigue cracking. This conclusion is supported by the higher magnification view, where the displacement of the inner surface of the header on opposite sides of the crack is seen clearly.

\section{Assessment of damage and of remaining life}

Assessment of the extent of damage depends on inspection, or on an estimation of the accumulation of damage based on a model for damage accumulation, or both. Sound planning of inspections is critical so that the areas inspected
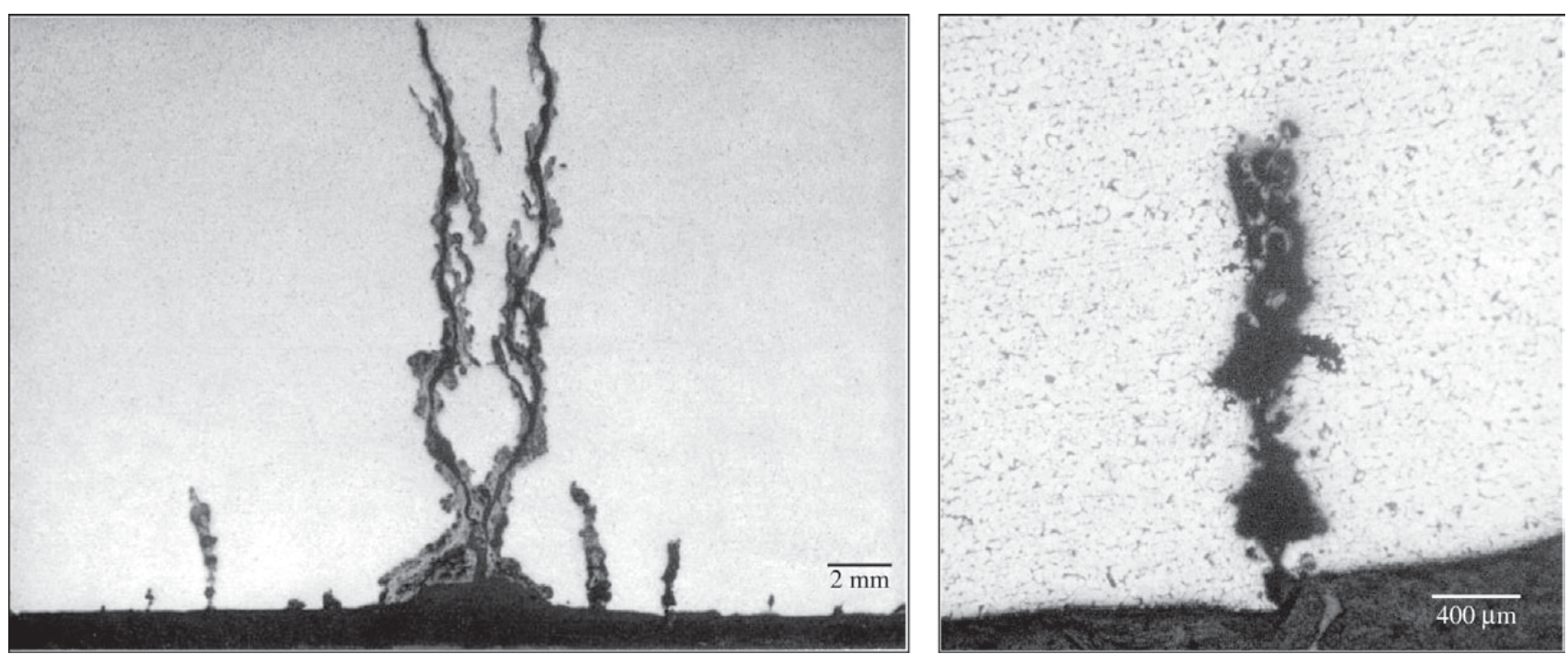

Figure 11. Cracking at a stub connection of a primary superheater header. 
are those where damage is expected to accumulate and the inspection techniques used are such as will provide reliable estimates of the extent of damage. If the extent of the damage is known or can be estimated, a reduced strength can be ascribed to the component and its adequacy to perform safely can be calculated.

The general philosophy for estimating fitness for service is outlined in the American Petroleum Institute (API) Recommended Practice 579, "Fitness-for-Service", the first edition of which was published in 2000. This document provides assessment procedures for the various types of defects to be expected in pressurized equipment in the refinery and chemical industry. The steps involved are as follows:

- Step 1: Identification of flaws and damage mechanisms.

- Step 2: Identification of the applicability of the assessment procedures applicable to the particular damage mechanism.

- Step 3: Identification of the requirements for data for the assessment.

- Step 4: Evaluation of the acceptance of the component in accordance with the appropriate assessment techniques and procedures.

- Step 5: Remaining life evaluation, which may include the evaluation of appropriate inspection intervals to monitor the growth of damage or defects.

- Step 6: Remediation if required.

- Step 7: In-service monitoring where a remaining life or inspection interval cannot be established.

- Step 8: Documentation, providing appropriate records of the evaluation made.

API 579 does not presently cover high temperature damage to components operating in the creep regime, this section still being under discussion and development. It should be noted in addition that the entire API 579 document is being re-developed in conjunction with the American Society of Mechanical Engineers (ASME) to provide a common document as a Standard issued by both societies.

For equipment operating at high temperature in the creep range, the principles outlined above are followed. Creep damage can be assessed by various procedures including those described earlier. Life estimates can also be made based on the predicted life at the temperature and stress that are involved, by subtracting the calculated life used up, and making an allowance for loss of thickness by oxidation or other damage. Recently there has been increased use of the procedures of continuum damage mechanics ${ }^{7}$ for creep damage and remaining life assessment. These ideas were initially developed for practical use by Penny ${ }^{15}$, and have been advanced further by Penny and Marriott ${ }^{16}$ and through the application of the Omega method developed by the Materials Properties Council ${ }^{17}$

The growth of cracks in components operating at high temperature that are detected can be estimated using established predictive methods as given, for example, by Webster and Ainsworth ${ }^{18}$. Additionally, various examples of simplified methods to predict safe life in petrochemical plant containing cracks have been published, for example in a reformer furnace ${ }^{19}$.

\section{References}

1. Ashby, M.F. A First Report on Deformation-Mechanism Maps, Acta Met., v. 20, p. 887-897, 1972.

2. Mohamed, F.A.; Langdon, T.G. Deformation Mechanism Maps: Their Use in Predicting Creep Behavior, J. Eng. Matls. and Technol., v. 98, p. 125-130, 1976.

3. Neubauer, B.; Wedel, U. Restlife Estimation of Creeping Components by Means of Replicas, in ASME International Conference on Advances in Life Prediction Methods, (Eds. D.A. Woodford, J.R. Whitehead, ASME, New York, 1983).

4. da Silveira, T.L.; Le May, I. Effects of Metallographic Preparation Procedures on Creep Damage Assessment, Materials Char., v. 28, p. 75-85, 1992.

5. Samuels, L.E.; Coade, R.W.; Mann, S.D. Precracking Structures in a Creep-Ruptured Low-Carbon Cr-Mo Steel: Their Nature and Detection by Light Microscopy and Scanning Electron Microscopy, Materials Char, v. 29, p. 343-363, 1992.

6. Toft, L.H.; Marsden, R.A. The Structure and Properties of $1 \% \mathrm{Cr}-0.5 \%$ Mo Steel After Service in CEGB Power Stations, in Structural Processes in Creep: Special Report 70, (Iron and Steel Institute, London, 1961).

7. Kachanov, L.M. Introduction to Continuum Damage Mechanics, (Martinus Nijhoff, Dordrecht, 1986).

8. Dyson, B. Use of CDM in Materials Modeling and Component Creep Life Prediction, J. Pressure Vessel Technol., v. 122, p. 281-296, 2000.

9. Furtado, H.C.; Collins, J.A.; Le May, I. Extending the Reliable Operation of Ageing Power Stations Through Analysis of Failed Components, in Ageing of Materials and Methods for the Assessment of Lifetimes of Engineering Plant-Cape '97, (Ed. R.K. Penny, Balkema, Rotterdam, 1996).

10. Honeycombe, R.W.K. Steels: Microstructure and Properties, (Arnold, London, 1981).

11. Johnson, J.M.; Berry, M.R.; Gutzheit, J. Zinc Embrittlement of Stainless Steels, in Embritlement by Liquid and Solid Metals, (Ed. M. H. Kamdar, Met. Soc. AIME, Warrendale, 1984).

12. The Flixborough Disaster, Report of the Court of Enquiry, (Dept. of Employment, HMSO, London, 1975).

13. Kamdar, M.H. Liquid Metal Embrittlement, in Metals Handbook, Ninth Edition, Vol. 13, Corrosion, (ASM International, Metals Park, 1987). 
14. Cottrell, A.H.; Swann, P.R. Technical Lessons of Flixborough, The Chemical Engineer, v. 4, p. 266-274, 1976.

15. Penny, R.K. The Usefulness of Engineering Damage Parameters During Creep, Metals and Materials, v. 8, p. 278-283, 1974.

16. Penny, R.K.; Marriott, D.L. Design for Creep, $2^{\text {nd }}$ Edition, (Chapman \& Hall, London, 1995).

17. Prager, M. Development of the MPC Omega Method for Life Assessment in the Creep Range, J. Pressure Vessel Technology, v. 117, p. 95-103, 1995.

18. Webster, G.A.; Ainsworth, R.A. High Temperature Component Life Assessment, (Chapman \& Hall, London, 1994).

19. Furtado, H.C.; Le May, I. Damage Evaluation and Life Assessment in High Temperature Plant: Some Case Studies, in Creep and Fatigue, (I. Mech,. E., London, 1996). 